\title{
Automatic Yeast Detection and Counting Using Computer Vision Techniques
}

\author{
João Victor Boechat Gomide \\ Programa de Pós-Graduação em \\ Sistemas de Informação e Gestão do \\ Conhecimento \\ Univeridade FUMEC \\ Belo Horizonte, Brasil \\ jvictor@fumec.br
}

\author{
Elton Vieira Cunha \\ Programa de Pós-Graduação em \\ Sistemas de Informação e Gestão do \\ Conhecimento \\ Univeridade FUMEC \\ Belo Horizonte, Brasil \\ eltonvieira.cunha@gmail.com
}

\author{
Guilherme Boechat Gomide \\ ACervA Mineira \\ Associação dos Cervejeiros Artesanais \\ de Minas Gerais \\ Belo Horizonte, Brasil \\ gbgomide@hotmail.com
}

\begin{abstract}
This paper presents the development of a computer vision system that automatically identifies and counts viable and inviable brewer's yeast, to improve the time and accuracy of results obtained compared to the manual expert counting method commonly performed in the brewing industry. The equipment used consists of a digital video camera coupled to an optical microscope, which transmits the captured images, in real time, to the computer. Two approaches were tested and implemented, one taking into account the morphology and color of yeasts, and the other using machine learning. Although there are programs that automatically count yeasts, this is the first application that makes use of convolutional neural network techniques with Yolo to identify yeasts, making the results more accurate and reliable compared to manual methods. Experiments were carried out to measure the performance and accuracy of the prototype, which are presented in this article.
\end{abstract}

Keywords - automatic yeast counting; computer vision; deep learning; Saccharomyces cerevisiae; yeast cell viability

\section{INTRODUÇÃO}

O objetivo do presente trabalho foi desenvolver um sistema de visão computacional que realizasse a identificação e a contagem automáticas de leveduras de cerveja viáveis e inviáveis e apresentasse os resultados finais de forma rápida e confiável. No sistema desenvolvido, utilizamos dois métodos de visão computacional distintos: o primeiro realiza a extração de regiões de uma imagem, que apresentam características comuns, por meio da biblioteca OpenCV [1], e o segundo método utiliza aprendizagem profunda, por meio do framework YOLO (You Only Look Once) [2], para identificação de leveduras viáveis e inviáveis. A pesquisa desenvolvida apresentou resultados positivos quanto ao seu uso, como é demonstrado neste artigo.

As leveduras Saccharomyces cerevisiae são utilizadas em vários segmentos da indústria, como na produção de cerveja e de pão. As leveduras dão às cervejas sabor, aroma e textura. É o agente biológico que transforma o mosto cervejeiro no produto final. $\mathrm{O}$ mosto cervejeiro é um termo usado na fermentação da cerveja e é o produto da mistura do malte triturado com água, a uma temperatura específica, na fase da mosturação ou brasagem [3].

Por meio da fermentação alcoólica, os açucares do mosto são transformados, pelas leveduras, em álcool. Dentre todas as leveduras que estão no mosto, apenas as leveduras vivas viabilizam o processo de fermentação. A quantidade de leveduras viáveis determina a medida da viabilidade celular no mosto. Esse é o aspecto mais importante no rendimento da fermentação alcoólica, pois quanto maior o número de leveduras viáveis, melhor será o desempenho do processo de fermentação [4]. Esse número é diferente para cada tipo de cerveja, mas a maneira de se chegar a ele de uma forma automática, rápida e precisa é o objetivo deste trabalho.

A separação e a contagem das leveduras ou colônias viáveis, que são empregadas no processo de produção de cerveja, são dispendiosas e propícias a falhas. Elas são realizadas de forma manual por especialistas, contando visualmente as leveduras no microscópio, em uma lâmina preparada com azul de metileno. Para estimar a proporção de células viáveis, que são incolores, e de inviáveis, que são azuis, quando estão em contato com o azul de metileno, em processo fermentativo, métodos baseados no plaqueamento ou na observação microscópica têm sido usados. Não existe, até o momento, um método absoluto para determinação da viabilidade celular de uma população de células de levedura e que forneça resultados totalmente seguros na determinação da mesma [5].

O método tradicional para contagem de microorganismos, utilizado na linha de produção, é a contagem manual em câmara de Neubauer, corada com azul de metileno. No entanto, a identificação de leveduras viáveis e inviáveis incorre em limitações geradas pela observação de cada operador, pelo cansaço, assim como também pelo tempo consumido para a identificação.

A implementação de um sistema automático de contagem de leveduras durante o processo de fermentação se faz necessário, para reduzir os erros recorrentes realizados manualmente por especialistas em atividades que exigem muito esforço físico e concentração, minimizando assim os custos e os riscos da produção.

$\mathrm{Na}$ próxima seção, é apresentada a metodologia aplicada às duas soluções implementadas para o software de identificação e contagem de leveduras viáveis e inviáveis. Em seguida, são discutidos os trabalhos relacionados, presentes na literatura. $\mathrm{Na}$ quarta seção, são apresentados os resultados obtidos neste trabalho, com suas métricas, e, em seguida, são debatidas as perspectivas futuras do presente trabalho e conclusões.

\section{MEtodologiA}

A preparação das lâminas para a contagem de leveduras foi feita no padrão utilizado pela indústria. O líquido a ser analisado foi obtido em diferentes etapas do processo de fermentação de cervejas artesanais. Ele é misturado com solução de azul de metileno a $0,1 \%$. Para a contagem de viabilidade, usa-se uma mistura de $50 \%$ dessa solução com $50 \%$ da amostra a ser analisada. A solução resultante é colocada em uma câmara de Neubauer, tradicionalmente 
utilizada nesse processo [5]. A câmara de Neubauer, também conhecida por hemocitômetro, é ainda o método mais utilizado em todo o mundo para a contagem de células, por causa de suas grades de referência, de diferentes tamanhos, marcadas no fundo da cavidade da câmara na lâmina.

A câmara de Neubauer, com a solução, é posicionada no microscópio, com aumento de 400X. A imagem resultante é capturada por uma câmera digital com 3 megapixels de resolução, acoplada à lente ocular do microscópio. Para cada campo de imagem, em ambos os aplicativos, as leveduras viáveis são contornadas por um quadrado verde $\mathrm{e}$ as leveduras inviáveis por um quadrado vermelho. A contagem é realizada automaticamente e é feita uma fotografia da imagem da câmera, com e sem as marcações. Posteriormente, cada fotografia foi observada em um monitor de alta resolução e as leveduras recontadas manualmente, por duas pessoas em momentos diferentes. O computador utilizado possui um processador Intel(R) Core(TM) i7-8750H CPU @ 2.20GHz $2.21 \mathrm{GHz}, 16 \mathrm{~GB}$ de memória RAM e uma placa de vídeo NVIDIA GeForce GTX 1060.

Para o aplicativo desenvolvido com inteligência artificial, foi preparado um banco de imagens para treinamento. Para o presente trabalho, foi construído previamente um banco com anotações de 43 imagens do microscópio, diferentes das posteriormente capturadas, durante os experimentos. As imagens continham um total de 872 leveduras, sendo 431 leveduras viáveis e 441 leveduras inviáveis. As imagens das leveduras individuais foram posteriormente rotacionadas $\mathrm{e}$ refletidas, para serem incluídas também no banco de imagens, porque elas contêm assimetrias devido às cicatrizes do processo de mitose pelo qual passam.

Os dois softwares para a detecção e contagem de leveduras viáveis e inviáveis foram desenvolvidos seguindo as melhores práticas para desenvolvimento e engenharia de software [6]. O código está escrito com as linguagens de programação $\mathrm{C}++$ e Python, com a implementação dos frameworks OpenCV [1] e YOLO [2]. e a biblioteca Qt [7], para a construção da interface gráfica.

$\mathrm{O}$ primeiro modelo proposto utiliza a função cv::SimpleBlobDetector, contida no framework OpenCV, que utiliza técnica de detecção de contorno. Também foi gerado um valor de limiar, ou de threshold, para a escala de cinza, e os pixels com valores maiores ou iguais ao do limiar são selecionados e os demais são descartados. Esse é um processo de segmentação da imagem, que é conhecida como segmentação por threshold, ou limiar. Com ele e algumas funções para otimizar a imagem, é possível separar as leveduras viáveis e inviáveis na imagem.

No processo de limiarização, os pixels conexos com valores acima do limiar, geram regiões conectadas, os chamados blobs. Até agora, foram testadas diversas técnicas de processamento de imagens para gerar os blobs e contar as leveduras, com diferentes filtros e algoritmos de segmentação da imagem. Os centros geométricos dessas regiões são determinados e, por meio desses centroides, pode se contar o número de leveduras, mesmo elas estando sobrepostas [8].

$\mathrm{Na}$ atualização do algoritmo, em sua segunda versão, com o aprendizado profundo, é aplicada uma única rede neural para a imagem completa. Esta rede divide a imagem em regiões e prediz probabilidades para cada região. Foi preparado um banco de imagens para fazer o treinamento de máquina e o resultado foi testado com fotografias do microscópio e, posteriormente, diretamente no microscópio, em tempo real.

A solução de inteligência artificial YOLO, que é de código aberto, apresentava características que poderiam contribuir para melhorar o software de detecção e contagem. A primeira versão do YOLO foi lançada em 2015 [9] e a terceira versão foi disponibilizada em 2018 [2]. O YOLO utiliza o aprendizado profundo com as redes neurais convolucionias em uma abordagem diferente, com as caixas delimitadoras e um processo de identificação que tem uma grande acurácia e velocidade. A principal implementação nova do YOLO é baseada no Darknet, que é um sistema de rede neural de código aberto, que define a arquitetura do YOLO.

Todo o fluxo de trabalho está dividido em cinco etapas:

1. Construção das bases de treinamento e de testes, com o recorte de imagens capturadas para esse projeto.

2. Definição das classes de leveduras.

3. Extração de características para a identificação das leveduras.

4. A etapa de treinamento utiliza o aprendizado de máquina, com o uso do framework YOLO (You Only Look Once) com a arquitetura Darknet.

5. Por último, a classificação em tempo real, a partir de streaming de uma câmera de vídeo acoplada em um microscópio.

Um conjunto de dados de imagens foi criado a partir de lâminas de neubauer preparadas com o corante de azul de metileno. A aplicação do projeto LabelImg [10] foi utilizada para processar as imagens e criar as anotações que identificam, nas amostras, o que deve ser entendido pelo processo de aprendizado de máquina como leveduras viáveis e inviávies. Essa aplicação foi escolhida por ser uma licença livre e de código aberto do Massachussets Institute of Technology (MIT).

A solução YOLO é indicada para executar o treinamento de máquina, uma vez que, assim como a aplicação LabelImg, é de código aberto, permitindo o aprendizado de máquina e a execução da identificação das imagens. É uma solução multiplataforma. Devido à escolha da solução YOLO, o treinamento de máquina é a de Rede Neural Convolucional, ou CNN, do inglês Convolutional Neural Network. Uma nova versão do software YOLO foi lançada em 2020 [11], mas se optou neste trabalho utilizar a versão desenvolvida por Redmon, que criou e desenvolveu o YOLO até a versão 3, de 2018. Estamos implementando a versão YOLOv4 atualmente.

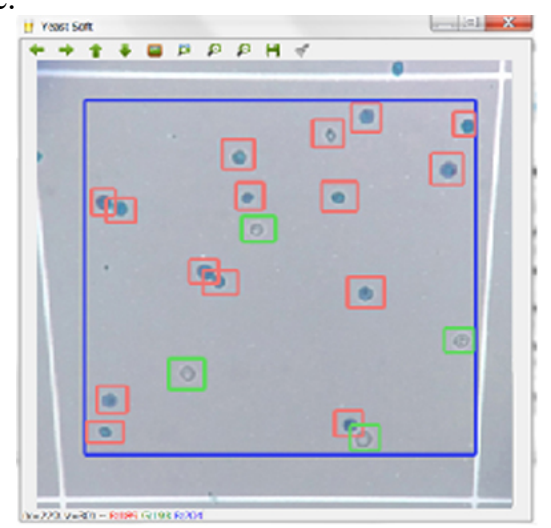

Fig. 1: Seleção da área de contagem de leveduras, na cor azul. Os quadrados vermelhos contornam as células inviáveis e os verdes as viáveis. Dos autores. 
O software desenvolvido neste trabalho buscou solucionar o problema de identificação de leveduras viáveis que ficam sobre a linha de marcação na câmara de Neubauer, criando uma área de seleção para que o operador possa marcar apenas a área de contagem de leveduras, a fim de excluir as divisórias contidas na lâmina (Figura 1), ou seja, as leveduras que estiverem fora da área de seleção, são descartadas.

Os dois métodos implementados são comparados com a identificação e a contagem realizadas manualmente por duas pessoas em situações diferentes, na imagem do computador, em uma tela de alta resolução. Ambos os softwares com diferentes métodos foram registrados no Instituto Nacional de Propriedade Intelectual (INPI) [12, 13].

\section{TRABALHOS RELACIONADOS}

Algumas tecnologias foram desenvolvidas a fim de possibilitar a contagem de células de leveduras de forma automática, como o Nucleo Counter ${ }^{\circledR}$ YC- $100^{\mathrm{TM}}$, da empresa dinamarquesa Chemometec. $\mathrm{O}$ equipamento consiste em uma câmera CCD e um microscópio de fluorescência, projetado para detectar sinais do corante fluorescente, iodeto de propídio (PI), que se liga ao DNA da levedura.

O iodeto de propídio é uma sonda fluorescente, que pode ser usada como corante celular, com o objetivo de distinguir células apoptóticas e necróticas de células saudáveis, com base na integridade da membrana. Esse agente é uma molécula que se intercala em qualquer DNA que esteja com a membrana celular permeável, para avaliar a viabilidade celular ou o conteúdo de DNA na análise do ciclo celular, ou em microscopia, para visualizar o núcleo e outras organelas contidos no DNA. [14]

Outro equipamento que realiza uma análise de viabilidade celular é o Vi-CELL, fabricado pela empresa norte-americana Beckman Coulter. O Vi-CELL realiza automaticamente a contagem e análise de célula por meio do corante azul de tripan, utilizando uma célula de fluxo contínuo e um sistema de análise de imagem.

O Vi-CELL' possibilita o manuseio de líquidos, que automatizam a aspiração de amostras e o manuseio de reagentes. As células são aspiradas dos copos de amostra, depois misturadas com o corante azul tripano e carregadas em uma célula de fluxo. Uma câmera digital captura imagens dessas células e algoritmos de processamento são aplicados aos resultados para distinguir entre células viáveis e não viáveis.

Além das contagens e viabilidades das células, as estimativas dos diâmetros e da circularidade das células também podem ser obtidas por meio do programa. O sistema automatizado de manuseio de líquidos reduz significativamente as variações que podem surgir do manuseio manual, e a automação do processamento de imagens elimina a subjetividade. Além disso, devido à faixa dinâmica estendida, as amostras podem ser analisadas até 107 células/mL sem diluição. Isso melhora a reprodutibilidade e a confiabilidade dos dados, o que é significativo, porque muitas decisões de fabricação são tomadas com base em contagens de células viáveis e/ou viabilidade de cultura [15].

O Nalco Yeast Activity Monitor, fabricado pela empresa americana Nalco Company, é um equipamento que possui reação rápida, geradora de fluorescência, que atinge enzimas de leveduras nativas. $\mathrm{O}$ equipamento possui uma sonda que é colocada em contato diretamente com a amostra preparada, proporcionando as taxas de atividade metabólica das leveduras [16].

Em [17] foi feita a análise de viabilidade de células em microscópio de fluorescência. No entanto, o método, apesar de sensível e simples, é oneroso e perigoso para o operador, pois os corantes utilizados são potencialmente cancerígenos.

$\mathrm{Na}$ área de visão computacional, um possível candidato para testar a viabilidade das leveduras é o programa de código aberto, CellProfiler ${ }^{\mathrm{TM}}$, que identifica e mede automaticamente uma variedade de objetos biológicos em imagens. $\mathrm{O}$ CellProfiler ${ }^{\mathrm{TM}}$ é um software de análise de imagem modular disponível gratuitamente, capaz de lidar com centenas de milhares de imagens. O software é também uma plataforma flexível e de código aberto para compartilhamento, teste e desenvolvimento de novos métodos realizados por especialistas em análise de imagem. Os módulos de identificação de células do CellProfiler ${ }^{\mathrm{TM}}$ contêm uma variedade de algoritmos publicados e testados para identificar células baseadas em fluorescência. Para identificar efetivamente os objetos agrupados, o CellProfiler ${ }^{\mathrm{TM}}$ contém uma estratégia modular de três etapas. Primeiro os objetos aglomerados são reconhecidos e separados; segundo, as linhas divisórias entre os objetos são encontradas; e, terceiro, alguns dos objetos resultantes são removidos ou mesclados com base em suas medidas, como, por exemplo, seu tamanho ou forma $[18,19]$.

As medições das células são acessíveis de várias maneiras: usando as ferramentas de visualização e plotagem de dados do CellProfiler, exportando em um formato de planilha delimitado por tabulações, que pode ser aberta em programas como o Microsoft Excel ou no OpenOffice Calc, exportando em um formato que pode ser importado para um banco de dados como Oracle ou MySQL ou diretamente no MATLAB.

O software é capaz de reconhecer as partículas por diferentes atributos das regiões de interesse (ROI), como a morfologia, cor, grau de correlação entre cores, textura, dentre outros. O software, porém, não é especializado em leveduras Saccharomyces cerevisiae e seu uso é normalmente aplicado na identificação de células, colônias, vermes Caenorhabditis elegans, entre outros micro-organismos. Isso dificulta adotar as técnicas citadas em avaliação de viabilidade de leveduras, por causa da necessidade de adaptação para a detecção e classificação das mesmas.

Os autores de [17] propuseram a validação do programa BioVic, com o objetivo de comparar os resultados obtidos na contagem automática de leveduras viáveis e inviáveis baseado em visão computacional, com os métodos de contagem por plaqueamento e visão humana. As amostras foram coradas com azul de metileno e as leveduras viáveis e inviáveis foram contadas em câmara de Neubauer. As imagens foram captadas por meio de um microscópio óptico e submetidas a reconhecimento de padrões com técnicas de visão computacional.

Os resultados mostraram que o BioViC contou melhor as leveduras inviáveis (azuis) porque as linhas que formam o retículo da câmara de Neubauer dificultaram a análise das imagens na contagem das células viáveis (incolores).

Em [20], se propõe o desenvolvimento de uma aplicação para a identificação e contagem de leveduras, separadamente em viáveis e inviáveis, utilizando 4 técnicas de visão 
computacional a partir do algoritmo do histograma de palavras visuais (Bag-of-Word - BoW), CCV (Color Coherence Vectors), CM (Color Moments), BoC (Bag-of-Color) e OpC (Opponent Color). O CCV extrai informação de cor através de regiões ou aglomerados de uma mesma cor. O CM extrai informação de cor através da média e variância aplicada em cada imagem. O BoC é um histograma de cor, cujo objetivo é extrair as frequências de determinadas cores. O OpC é uma variante que aplica o BoW em cada canal de cor.

Os autores em [21] utilizaram e avaliaram a técnica FRT (Fast Radial Transform) para contar colônias de leveduras em placas de Petri. Esta técnica foi utilizada para localizar leveduras na imagem, onde o maior problema foi contar as leveduras de forma separada, uma vez que cada colônia possui um grupo de leveduras, que muitas vezes apresentavam sobrepostsa umas as outras. Os testes foram realizados com 245 imagens contendo colônias de leveduras de diferentes formas. Os resultados mostraram que a técnica FRT apresentou uma taxa de erro menor que 0.04 para a contagem de colônias de leveduras.

A pesquisa apresentada em [22] descreve o desenvolvimento de um sistema semiautomático de contagem de micro-organismos utilizando técnicas de processamento de imagens. A metodologia se baseia na técnica tradicionalmente utilizada em microbiologia, de contagem de células em câmara de Neubauer. O sistema captura imagens de um microscópio óptico por meio de uma câmera de vídeo e envia a imagem para um computador. Neste, a imagem é digitalizada, pré-processada, com o intuito de remover o fundo da imagem e a binariza, utilizando um algoritmo de limiarização e depois quantifica os micro-organismos existentes em uma amostra usando um algoritmo de rotulação de áreas conectadas.

O sistema apresentou alguns erros na contagem de leveduras devido a uma ampliação demasiado exagerada na imagem, fazendo com que as células ficassem com o centro muito claro, de forma a contar duas ou mais células onde só existia uma. Outros dois problemas que geraram erros de contagem foram a concentração de células sobre as linhas de marcação e a falta de foco.

\section{RESUltados OBTIDOS}

Durante os experimentos realizados para se obter a viabilidade celular, foi capturado um total de 40 imagens com uma câmera digital de vídeo, conectada ao microscópio óptico, para avaliar a acurácia do método, tanto utilizando a visão computacional com a biblioteca OpenCV como com o framework YOLO. O resultado da contagem e detecção das leveuras foram obtidos em menos de três segundo para os dois métodos.

Como mostra a figura 2, na primeira contagem, o framework YOLO identificou 53 leveduras vivas e 53 leveduras mortas. A contagem é realizada apenas dentro da área de seleção (linha azul). As leveduras que estão fora ou em cima da área de seleção são, portanto, descartadas pelo software. As leveduras viáveis estão marcadas com a cor verde e as leveduras inviáveis com a cor vermelha.

$\mathrm{Na}$ segunda amostra, ainda utilizando o framework YOLO, obtivemos 48 leveduras vivas e 46 leveduras mortas, como na figura 3.

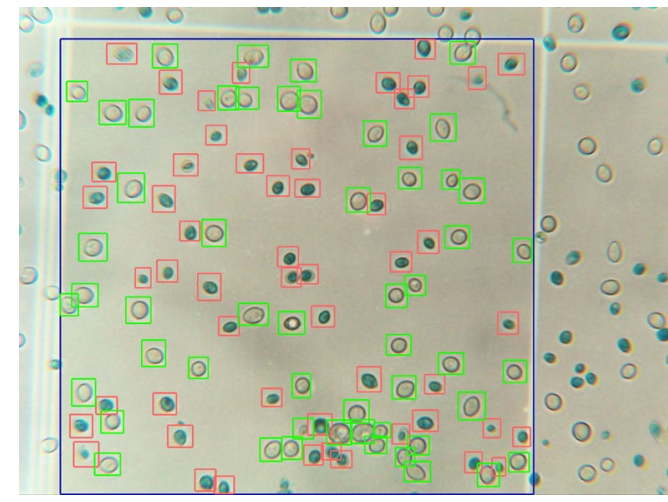

Fig. 2: Primeira imagem para teste de viabilidade celular com YOLO. Células viáveis estão contornadas por um quadrado verde, células inviáveis, vermelho.

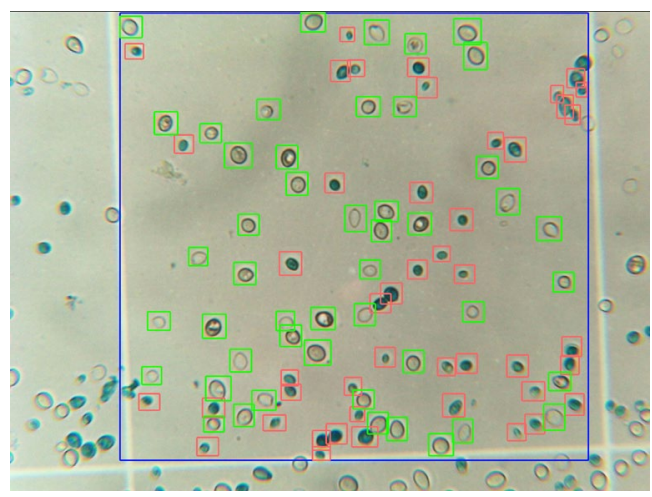

Fig. 3: Segunda imagem para teste de viabilidade celular com YOLO.

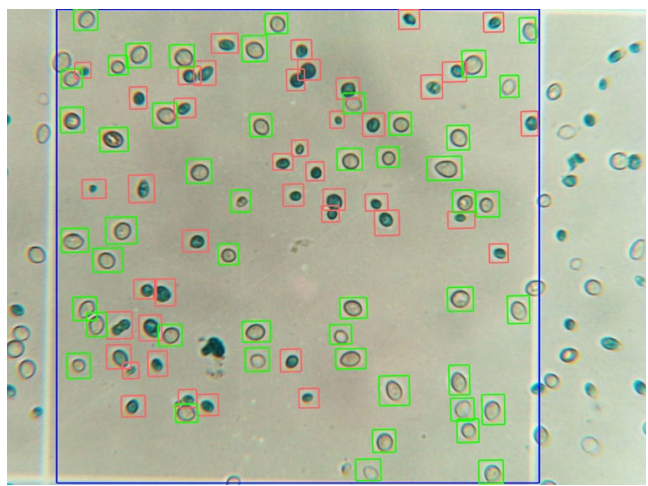

Fig. 4: Terceira imagem para teste de viabilidade celular com YOLO.

$\mathrm{Na}$ terceira amostra, utilizando o framework YOLO, gerou o resultado de 48 leveduras vivas e 42 leveduras mortas, como na figura 4.

Depois que as 40 imagens foram analisadas e contadas utilizando a aprendizagem profunda, o mesmo método foi adotado para a identificação de leveduras por meio da biblioteca de visão computacional OpenCV. A seguir são mostradas a identificação das primeiras imagens coletadas.

A primeira amostra processada pelo OpenCV, identificou 52 leveduras vivas e 52 leveduras mortas, ou seja, uma levedura viável e uma levedura inviável a menos que o método de Deep Learning, como na fig. 5. Isso se deve ao fato do OpenCV não conseguir separar muito bem as leveduras que estão agrupadas, como mostra as imagens. 


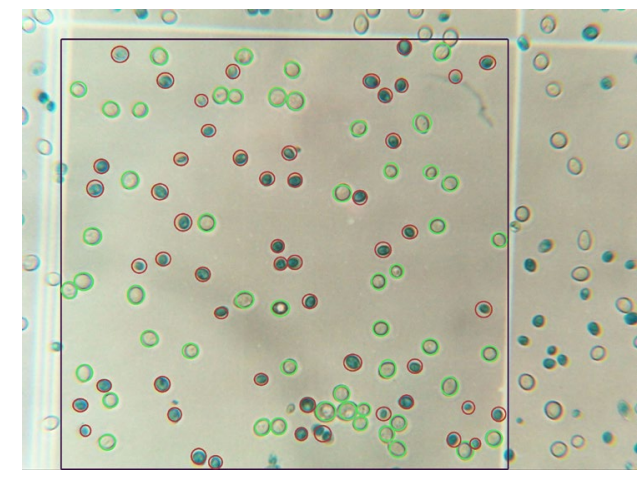

Fig. 5: Primeira imagem para teste de viabilidade celular com OpenCV. Células viáveis estão marcadas de verde, células inviáveis, vermelho.

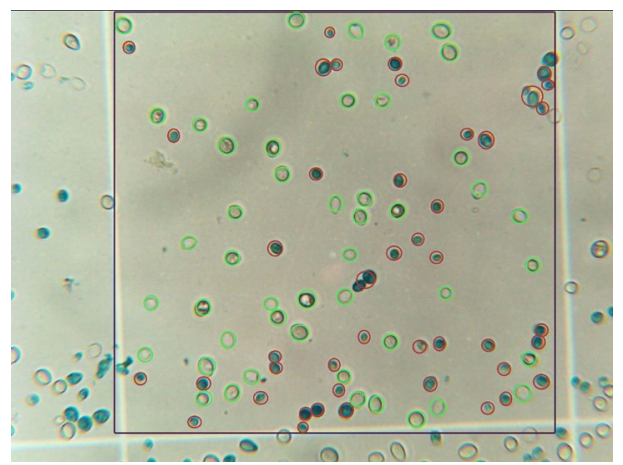

Fig. 6: Segunda imagem para teste de viabilidade celular com OpenCV.

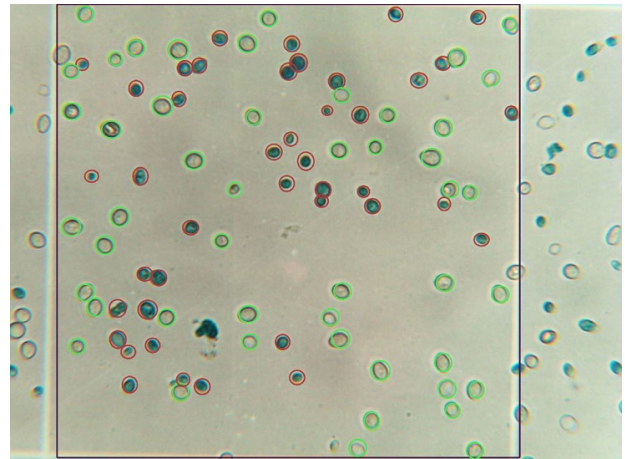

Fig. 7: Terceira imagem para teste de viabilidade celular com OpenCV.

$\mathrm{Na}$ segunda amostra analisada pelo OpenCV, duas leveduras inviáveis não foram contabilizadas devido ao agrupamento de algumas células. Foram identificadas, portanto, 48 leveduras vivas e 44 leveduras mortas, como na fig. 6 .

A terceira amostra, utilizando a biblioteca OpenCV, identificou 48 leveduras vivas e 42 leveduras mortas, como na fig. 7. Todas as 40 imagens foram analisadas, identificadas e contadas pelos dois métodos desenvolvidos por este trabalho, assim como por um especialista, manualmente.

Os experimentos foram realizados em conformidade com a metodologia aplicada descrita anteriormente, submetidos à análise estatística do teste do erro quadrático Qui-Quadrado $\left(\chi^{2}\right)$, sendo o nível de significância estabelecida em 0,05 (Tabela 1), com a matriz de confusão, como mostrada nas tabelas 2 e 3 e explicada a seguir.

O teste de independência Qui-Quadrado é usado para determinar se existe uma associação entre a variável de linha e de coluna, em uma tabela de contingência construída a partir de dados da amostra. A hipótese nula é de que as variáveis não estão associadas, isto é, eles são independentes. A hipótese alternativa é de haver uma associação estatisticamente significativa entre as variáveis.

Verifica-se que o resultado não é significativo em $p>$ 0,05 . Portanto, não foi encontrada diferença significativa entre a análise manual, realizada como foi descrita anteriormente, e o software desenvolvido, que utiliza os métodos de visão computacional e de aprendizado profundo, para contagem de leveduras. Com base neste resultado, considera-se que o sistema se mostra eficiente quando comparado com o trabalho do especialista.

Segundo [23], a matriz de confusão, também conhecida como matriz de erro, é uma maneira de resumir o desempenho de um classificador para tarefas de classificação binária. Já Congalton [24] define como sendo uma das técnicas mais utilizadas de avaliação de acurácia da classificação de dados. Ela contém informações sobre a classificação realizada por um determinado sistema, onde seus dados demonstram o desempenho de tais sistemas.

A matriz de confusão é uma tabela que mostra as frequências de classificação para cada classe do modelo:

- Verdadeiro positivo: ocorre quando a levedura viável é identificada pelo software, como previsto pela contagem manual.

- Falso positivo: ocorre quando a levedura viável não é identificada pelo software, diferente da contagem manual.

- Verdadeiro negativo: ocorre quando a levedura inviável é identificada pelo software, como previsto pela contagem manual.

- Falso negativo: ocorre quando a levedura inviável não é identificada pelo software, diferente da contagem manual.

Observando a tabela 2, podemos perceber que o sistema com métodos de aprendizado de máquina previu a identificação correta de leveduras viáveis 1364 vezes e de leveduras inviáveis 808 vezes. Portanto, 3 leveduras viáveis não foram identificadas corretamente e 63 leveduras inviáveis não foram identificadas corretamente.

Nesse contexto, nosso modelo teve uma acurácia de $97,05 \%$, pois acertou 2172 das 2238 previsões. A acurácia é a razão entre o somatório das previsões corretas (verdadeiros positivos e verdadeiros negativos) sobre o somatório total das previsões.

TABELA 1: NÚMERO TOTAL DE LEVEDURAS CONTADAS ATRAVÉS DE MICROSCÓPICO $(\mathrm{N}=0,05)$

\begin{tabular}{|c|c|c|c|c|}
\hline Contagm & $\begin{array}{l}\text { Leve- } \\
\text { duras } \\
\text { vivas }\end{array}$ & $\begin{array}{l}\text { Leve- } \\
\text { duras } \\
\text { mortas }\end{array}$ & $\begin{array}{c}\text { Chi- } \\
\text { Quadrado }\end{array}$ & $p$ valor \\
\hline Manual & 1367 & 871 & & \\
\hline OpenCV & 1341 & 800 & 1.6892 & 0.429737 \\
\hline YOLO & 1364 & 808 & & \\
\hline
\end{tabular}

TABELA 2: MATRIZ DE CONFUSÃO COM APRENDIZADO DE MÁQUINA 


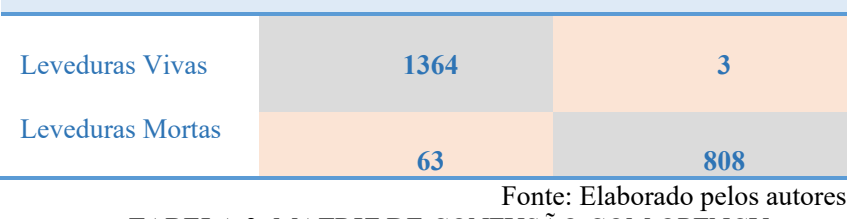

TABELA 3: MATRIZ DE CONFUSÃO COM OPENCV

Leveduras Vivas

Leveduras Mortas

\begin{tabular}{lcc}
\hline Leveduras Vivas & 1341 & 26 \\
\hline Leveduras Mortas & 71 & 800 \\
\hline
\end{tabular}

Fonte: Elaborado pelos autores

Para calcular a viabilidade celular, calcula-se a porcentagem de leveduras viáveis sobre o total de leveduras contidas na amostra. Para a amostra citada acima, obtivemos o total de 2172 registradas pelo sistema, sendo 1364 leveduras vivas. Portanto a viabilidade celular é de $62,79 \%$.

Uma nova matriz de confusão foi gerada para avaliar o nível de acerto do método cv::SimpleBlobDetector, contida no framework OpenCV. Como observado na tabela 3, a função previu corretamente 1341 leveduras viáveis e 800 leveduras inviáveis. Nesse caso, 26 leveduras viáveis e 71 leveduras inviáveis não foram identificadas pela função do OpenCV. A viabilidade celular é de 62,63\%. O modelo teve uma acurácia de 95,66\%, pois acertou 2141 das 2238 previsões.

Para calcular a viabilidade celular obtida pela contagem manual, devemos pegar a quantidade total de leveduras vivas, multiplicar por 100 e depois dividir o resultado pela quantidade total de leveduras, ou seja, o método manual obteve $61,08 \%$ de viabilidade celular.

\section{Conclusões e PeRsPectivas}

Esse trabalho demonstra dois métodos automáticos para identificar e contar leveduras viáveis e inviáveis, gerando resultados com grande precisão e rapidez. Devido à acurácia e precisão dos resultados, os dois métodos se apresentam como uma forma de substituir a contagem manual de leveduras nas usinas de açúcar e álcool, demonstrando ser possível automatizar o processo de contagem de leveduras durante a fermentação de cerveja, de forma rápida e precisa.

$\mathrm{O}$ método de aprendizagem profunda, utilizando o framework YOLOv3, identificou e contou melhor as leveduras inviáveis e viáveis em relação ao método de contagem por visão computacional, baseado em técnica de detecção de contorno da biblioteca OpenCV.

Em relação ao método de contagem manual, os dois métodos utilizados por essa pesquisa, para identificação e contagem automática de leveduras, mostrou resultados que se aproximam do resultado obtido manualmente, de forma a garantir a confiabilidade na obtenção da viabilidade celular durante a fermentação do mosto para produção de cerveja.

A implementação de métodos automáticos, na linha de produção de cerveja, vai reduzir custos e aumentar a eficiência do processo de contagem de leveduras, em um tempo mais reduzido.

\section{AGRADECIMENTOS}

Os autores gostariam de agradecer o Conselho de Desenvolvimento Científico e Tecnológico (CNPq) e a Fundação de Amparo à Pesquisa do Estado de Minas Gerais (FAPEMIG) pelo apoio financeiro recebido.

\section{REFERÊNCIAS}

[1] OpenCV (2021), biblioteca de código aberto de visão computacional, disponível em https://opencv.org/, acessado em 25 de setembro de 2021

[2] J. Redmon, (2018) YOLOv3: An Incremental Improvement, arxiv.org, arXiv:1804.02767.

[3] CARVAlHo, G. B. M.; BENTO, C. V.; SILVA, J. B. A. (2006) Elementos Fundamentais no Processo Cervejeiro: $1^{\text {a }}$ parte- As leveduras. Revista Analítica. São Paulo, 2006.

[4] BRIGGS, D. E. Malts and malting. London: Blackie Academic and Professional; Gaithersburg:Aspen, 1998. 796p.

[5] CECCATO-ANTONINI, S. R. (2010) Microbiologia da fermentação alcoólica: a importância do monitoramento microbiológico em destilarias. São Carlos: EdUFSCar, Vol. 27, p. 120, N 5, 2010.

[6] MCCONELL, S. (2004). Code Complete: A practical handbook of software-construction practices. Second Edition. Microsoft Press, Redmond, WA, EUA.

[7] Qt (2021), portal oficial do software de desenvolvimento Qt, em https://www.qt.io/, acessado em 25 de setembro de 2021.

[8] GONZALEZ, Rafael C. e WOODS, Richard E. (2010) Processamento Digital de Imagens. São Paulo: Pearson Education do Brasil. 2010.

[9] J. Redmon, S. Divvala, R. Girshick and A. Farhadi, You Only Look Once: Unified, Real-Time Object Detection (2015), arxiv.org, arXiv:1506.02640.

[10] LabelImg (2021), projeto de código aberto disponível no GitHub em https://github.com/tzutalin/labelImg, acessado em 25 de setembro de 2021 .

[11] A. Bochkovskiy, C. Y. Wang, H.-Y. M. Liao. (2020). YOLOv4: Optimal Speed and Accuracy of Object Detection), arxiv.org, arXiv:2004.10934.

[12] GOMIDE, J.V.B.; CUNHA, E. V.; YeastSoft, counting yeast cells automatically. 2018. Patente: Programa de Computador. Numero do "YeastSoft, counting yeast cells automatically", Instituição de registro: INPI - Instituto Nacional da Propriedade Industrial.
INP

[13] GOMIDE, J. V. B.; CUNHA, E. V. ; GOMIDE, G. B. YeastSmartCount, counting yeast cells automatically with artificial intelligency. 2019. Patente: Programa de Computador. Número do registro: $512019001821-4$, data de registro: 31/07/2019, Instituição de registro: INPI - Instituto Nacional da Propriedade Industrial.

[14] RASCHKA, S. (2014). An Overview of General Performance Metrics of Binary Classifier Systems. arXiv preprint arXiv:1410.5330

[15] THOLUDUR, A.; GIRON, L.; ALAM, K.; THOMAS, T.; GARR, E.; WEATHERLY, G.; KULOWIEC, K.; QUICK, M.; SHEPARD, S. (2006). Comparing automated and manual cell counts for cell culture applications. Bioprocess Int. 2006, 4, 28-34.

[16] MONGELO, A. I., DA SILVA, D. S., QUINTA, L. N. B., PISTORI, H., E CEREDA, M. P. (2011). Validação de método baseado em visão computacional para automação de contagem de viabilidade de leveduras em indústrias alcooleiras. páginas 17-21 Outubro, Bento Gonçalves, RS

[17] CORRÊA, B. et al. Método fluorescente (diacetato de fluoresceína e brometo de etídio) para o estudo da viabilidade de cryptococcus neoform.

[18] CARPENTER, A.E. ET AL. (2006) CellProfiler: image analysis software for identifying and quantifying cell phenotypes. Genome Biol. 7, R100.

[19] LAMPRECHT M.R.; SABATINI D.M.; CARPENTER A.E.(2007). CellProfiler: free, versatile software for automated biological image analysis. BioT(echniques, v. 42, pp. 71- 75 .

[20] SOUZA J. S.; (2015) Identificação de Viabilidade de leveduras com corante vital utilizando histogramas de palavras visuais em imagens coloridas. Dissertação de Mestrado da UFMS.

[21] SCHIER, J. K.; B. (2011) Automated Counting of Yeast Colonies using the Fast Radial Transform Algorithm. Bioinformatics, p. 22-27, 2011.

[22] LUCARINI A. C.; SILVA L. A.; BIANCHI R. A. C (2011). Um sistema para a contagem semi-automática de microorganismos. PESQUISA \& TECNOLOGIA FEI - No $26 \mathrm{p} 36-40$. Disponivel em http://fei.edu.br/ rbianchi/publications/RevistaFEI2004-a.pdf acessado em 06/01/2019.

[23] RASCHKA, S. (2014). An Overview of General Performance Metrics of Binary Classifier Systems. arXiv preprint arXiv:1410.5330.

[24] CONGALTON, R. G. (1991) A review of assessing the accuracy of classifications of remotely sensed data. Remote Sensing of Environment, v. 49, n. 12, p. 1671-1678 